\title{
BODY PROPORTIONS IN CHILDREN AND ADOLESCENTS WITH DOWN'S SYNDROME
}

\author{
Leonardo Trevisan Costa ${ }^{1,2}$, Fábia Freire ${ }^{4}$, Fábio Bertapelli4, \\ Luis Felipe Castelli Correia de Campos ${ }^{5}$, Luiz Gustavo T. Fabrício dos Santos ${ }^{5}$, \\ José Irineu Gorla ${ }^{3}$
}

\begin{abstract}
The present study aimed to evaluate the body proportions of sitting height and leg length in children and adolescents with Down's syndrome (DS). The sample consisted of 99 individuals with DS (40 girls with an average age of $11.45 \pm 2.6$ years and 59 boys with an average age of $12.07 \pm 3.0$ years). The following parameters were studied: chronological age, height, sitting height and leg length. The body proportions of each segment were calculated using body indices and the Phantom model. For the statistical analysis, the normality test and descriptive analyses of central tendency and dispersion were performed, and Student's t-test was used. For all treatments, the statistical software program SPSS version 13.0 was used, and a significance level of $p<0.05$ was set. The body proportion of the upper and lower segments of children and adolescents with DS differed from those of the typical population in terms of leg length, whereas the seated height values of individuals with DS twere similar to those of individuals without DS.
\end{abstract}

Key words: body proportion; Down's syndrome; growth.

\section{INTRODUCTION}

The phenotype of Down syndrome (DS) is complex and varies among individuals. This phenotype may include a combination of several characteristics, such as brachycephaly; brachydactyly; epicanthic fold; duodenal atresia; hypotonia; flat nasal bridge; communication difficulties; short stature; broad hands; clinodactyly; increased distance between the first and second toes; small, flat and oval shaped head; short legs; and intellectual disabilities ${ }^{1-3}$. Individuals with DS also have an increased incidence of cardiovascular diseases, endocrine alterations, immune defects, nutritional disorders and leukemia and a higher risk of infections ${ }^{4}$.

DS originates from the inadequate separation of chromosome 21, which may occur in the gamete formation phase (egg or sperm) or immediately after fertilization in meiosis or in mitosis, respectively. Chromosome separation may occur in three ways: free trisomy 21 ; translocation between chromosomes 21 and 14 and/or translocation between chromosomes 21, 21 and 22; or chromosomal mosaicism ${ }^{5,6}$.

Studies of body proportions in individuals with DS are scarce and often address only adults' height ${ }^{7-9}$. Few investigations have evaluated other anthropometric variables. In those studies, the authors showed that the average growth rate during adolescence is slightly reduced in people with DS. Additionally, the authors reported that the shorter height observed in the DS population was mostly caused by smaller increases in lower limb growth throughout the study period ( 8 - 18 years) relative to the typically developing population ${ }^{10}$.

Thus, the present study aimed to evaluate the body proportions for seated height and leg length in children and adolescents with Down syndrome in Brazil.

\footnotetext{
MSc Professor at the Votuporanga University Center (Centro Universitário de Votuporanga, UNIFEV).

PhD student in adapted physical activity, Campinas State University (Universidade Estadual de Campinas - UNICAMP).

MSc student in Physical Activity, Adaptation and Health, UNICAMP.

MSc Professor at the Department of Adapted Physical Activity Studies, UNICAMP 3.

Master of Science in Adapted Physical Activity, UNICAMP 5.

Department and Institution: School of Physical Education, Campinas State University (Universidade Estadual de Campinas, UNICAMP)

Development agency: National Counsel of Technological and Scientific Development (Conselho Nacional de Desenvolvimento Científico e Tecnológico - CNPq)

Corresponding author: leonardotrevizan@hotmail.com
}

Suggested citation: Costa LT, et al. Body proportions in children and adolescents with Down's Syndrome; 2013; 23(2): 198-202 Manuscript submitted Oct 20 2012, accepted for publication Mar 202012. 


\section{METHODS}

A total of 99 children and adolescents with Down syndrome (DS) were assessed. Forty of the subjects were girls with an average age of $11.45 \pm 2.6$ years, and 59 were boys with an average age of $12.07 \pm 3.0$ years. All of the participants were attending specialized educational institutions located in the metropolitan region of Campinas, São Paulo, Brazil. The study followed the guidelines and standards that regulate human research (Law Number 196/96) and was approved by the Research Ethics Committee of the State University of Campinas (Universidade Estadual de Campinas, UNICAMP; n.558/2010). An independent and informed consent form that would authorize the children's participation in the study was sent to the children's parents or guardians.

The following parameters were assessed: chronological age (years), height, seated height and leg length. The karyotype (mosaicism, translocation or simple trisomy) and the presence or absence of pathologies associated with the syndrome was not analyzed.

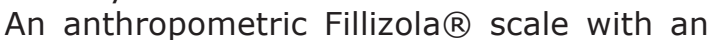
accuracy of 100 grams was used to measure body mass. The participants were weighed in a standing posture with a horizontal gaze axis. The subjects wore the minimum possible clothing (only the educational institution uniform), the weight of which was not discounted.

Height was measured using a metal stadiometer with a scale accuracy of $0.1 \mathrm{~cm}$. A metal cursor determined the participant's height, which was measured with the participant wearing the educational institution uniform. The participants were weighed in an upright position with a horizontal gaze, the upper limbs alongside the body, heels together and buttocks, torso and head touching the vertical plane of the stadiometer.

The sitting height was measured with the aid of a $50-\mathrm{cm}$-tall wooden bench. The participants had their buttocks supported, their torso and head along the vertical plane of the stadiometer and their hands resting on their thighs. The head was slightly stretched to stand out from the shoulders, and the gaze axis was horizontal. The same metal stadiometer with 0.1$\mathrm{cm}$ accuracy that was used to perform the height measurements was used to measure the sitting height. The leg length measurement was determined by the difference between the height and the sitting height.

The proportions of the body segments were assessed using body indices and the Phantom model. The Phantom model was designed by Ross and Wilson, who proposed a bilaterally symmetric and unisex human reference based on anthropometric studies conducted in large populations ${ }^{11}$.

To make this type of analysis more operational, the authors applied the $Z$ score concept to the proportionality analysis. The $Z$ score ex- presses the distance from a point on the bell curve of probabilities to its midpoints, as represented by the mean. In proportionality, this index expresses the distance, in terms of standard deviation, between the numerical value of a variable and the average Phantom model for that measure. The formula for calculating the $Z$ score is

$$
Z=1 / s\left[L(170,18 / E)^{d}-P\right]
$$

\section{where}

$Z$ = the $Z$ index of the studied measure.

$\mathrm{s}=$ the typical standard deviation of the Phantom model for the variable studied.

$\mathrm{L}=$ the measurement for the studied individual.

$170,18=$ the proportionality constant for the model height.

$\mathrm{E}=$ the height of the individual studied. studied.

$\mathrm{P}=$ the Phantom value for the variable

$d=1$ for linear measures, $d=2$ for surface measures, $d=3$ for mass measures.

(Ross and Wilson, 1974).

This formula aims to adjust all of the measurements to a common height geometrically, making it possible to study the proportions, regardless of the real size. The Phantom variables are unimodal, i.e., $Z=0.0$ is the mode. Therefore: tom".

$$
\mathrm{Z}=0.0 \text { indicates "same proportion as Phan- }
$$

$Z>0.0$ indicates "proportionally higher than Phantom".

$Z<0.0$ indicates "proportionally lower than Phantom."

(de la Rosa and Rodriguez-Añes, 2002).

The proportionality indices for sitting height and leg length were also used. These indices can be defined as scores resulting from mathematical associations between the values of two anthropometric dimensions observed in the same evaluated subject. These scores are adjusted as percentage values that represent the lowest measured value divided by the highest one ${ }^{13}$ (Guedes et al., 2006). Thus, the following equations were used:

Sitting height index $=$ sitting height $(\mathrm{cm}) \mathrm{x}$ 100/height $(\mathrm{cm})$ height $(\mathrm{cm})$

Leg length index $=$ leg length $(\mathrm{cm}) \times 100 /$

Subsequently, based on descriptive studies developed in different parts of the world ${ }^{13}$, the reference indices were used for the analysis of the body indices of both sexes and for both the sitting height and the leg-length analyses.

The Kolmogorov-Smirnov test and descriptive analyses of central tendency (mean) and dis- 
persion (standard deviation) were used for the initial treatment of the data. After the data's normality was confirmed, Student's t-test was used to verify possible significant differences between the sexes.

The software program SPSS 13.0 for Windows was used for all analyses, and significance was set at $\mathrm{p}<0.05$.

\section{RESULTS}

The results of the first Brazilian study of body proportions in children and adolescents with DS reflect a sample of subjects in different age groups who were assessed a single time. Factors that may have influenced growth in this sample were not controlled.

Table 1: Descriptive data regarding the mean, standard deviation and minimum and maximum values for the sample studied in Campinas, SP, Brazil

$\begin{array}{ccccccc} & \text { Mean } & \begin{array}{c}\text { Boys }(\mathbf{n = 5 9 )} \\ \text { Minimum }\end{array} & \text { Maximum } & \text { Mean } & \begin{array}{c}\text { Girls } \mathbf{( n = 4 0 )} \\ \text { Minimum }\end{array} & \text { Maximum } \\ \text { Age (years) } & 12.07 \pm 3 & 6 & 18 & 11.45 \pm 2.6 & 7 & 16 \\ \text { Weight (kg) } & 44.03 \pm 117.4 & 20 & 84.5 & 44.1 \pm 16.4 & 18.6 & 93.6 \\ \text { Height (cm) } & 136.40 \pm 15.5^{*} & 109.5 & 169.2 & 129.03 \pm 11.8 & 102 & 142.3 \\ \text { SH (cm) } & 71.62 \pm 10.2^{*} & 51 & 89.4 & 67.2 \pm 9 & 50.9 & 86.2 \\ \text { LL (cm) } & 64.77 \pm 8.1 * & 52.3 & 86 & 61.69 \pm 6.2 & 50 & 74.7 \\ \text { Zsh } & -0.34 \pm 1.3 & -4.7 & 3.2 & -0.50 \pm 1.4 & -4.19 & 2.89 \\ \text { Zll } & 0.39 \pm 1.5 & -3.7 & 5.43 & 0.54 \pm 1.5 & -3.3 & 4.5 \\ \text { Ish } & 52.43 \pm 3.6 & 40.6 & 62 & 51.96 \pm 3.9 & 42.1 & 61 \\ \text { Ill } & 47.56 \pm 3.6 & 37.9 & 59.3 & 47.94 \pm 3.7 & 38.9 & 57.1\end{array}$

SH: sitting height; LL: leg length. Zsh: sitting height Phantom score; Zll: leg length Phantom score; Ish: sitting height body index; Ill: leg length body index.

Table 1 shows the mean, standard deviation and minimum and maximum values for both sexes. Data for body proportions are shown in absolute values, $Z$ scores (Phantom) and percentages based on the body indices.
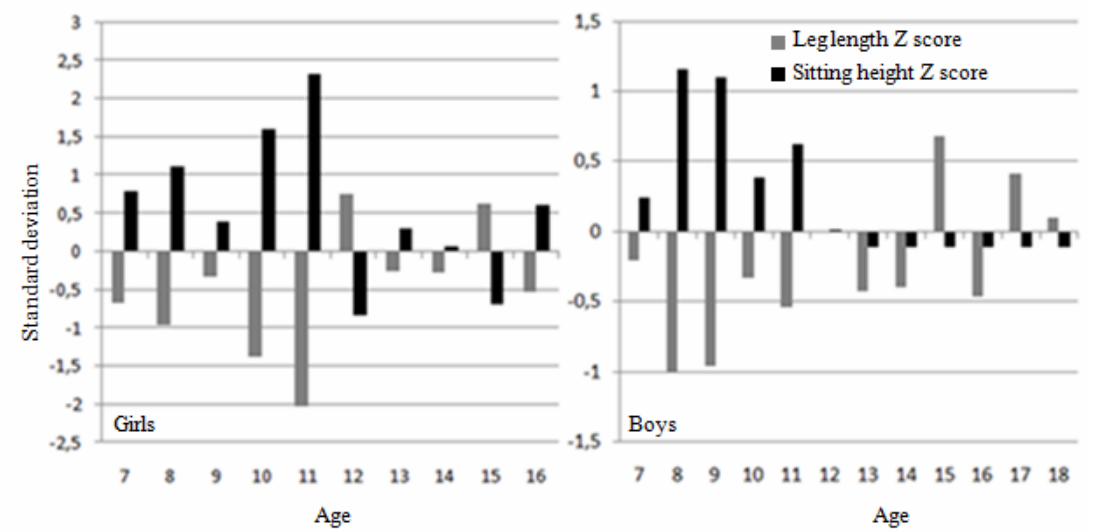

Figure 1: Body proportions of girls and boys with DS based on chronological age and Phantom reference.
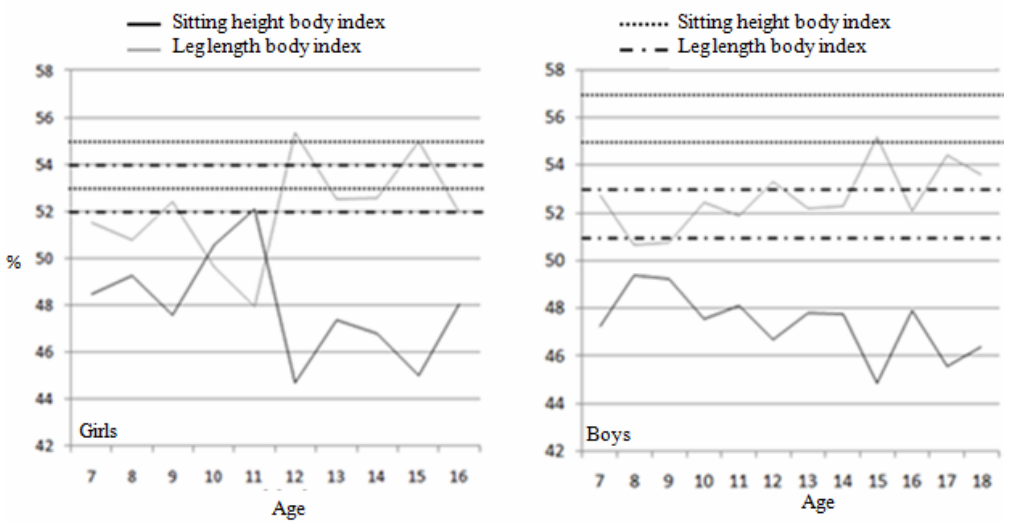

Figure 2: Body proportion of girls and boys with DS based on chronological age, classified according to Phantom reference values. 


\section{DISCUSSION}

These results regarding the body proportions of children and adolescents with Down's Syndrome reflect a sample of subjects in different age groups assessed a once. The boys had significantly higher mean values for height, sitting height and leg length than the girls.

Regarding body proportion, Figure 1 shows the sample's standard deviation (SD) values based on the Phantom reference. SDs greater than or equal to -2 and +2 (score $+2<z>-2$ ) are considered normal. According to Figure 1, the only point at which the girls had $z$ scores above +2 SD was for leg length at 11 years of age, which coincided with the -2 SD point for sitting height. The boys had sitting heights and leg lengths within the normal values of the reference population.

Figure 1 shows that the variables had greater proximity to the normative values as chronological age advanced, and the highest standard deviations occurred between 10 and 11 years for girls and between 8 and 9 years for boys.

The body index analyses (Figure 2) showed that girls never reached the range of normative values (52 to 54) for leg length and had sitting height values similar to the reference population's normal values for sitting height (53 to 55) after the age of 11 years. Similarly, the boys' body indices were close to the reference values for sitting height (51 to 53). However, these subjects did not have leg-length body indices within the normal values of the reference population (55 to 57).

It is difficult to interpret body proportion data using the Phantom method because of the height equation value used $(170,18)$. In most cases, people with DS do not reach similar final height values. Additionally, there may be wide variations in growth among individuals with DS, depending on the type of genetic alteration that they have (simple trisomy, mosaicism or translocation). An American study evaluated the growth of 730 children and adolescents aged 0 to 18 years with DS and found that the final height of both sexes was reduced by 2 standard deviations compared with the reference population ${ }^{7}$. In another study, the authors analyzed 85 individuals with DS aged 0 to 20 years and reported mean values of $153.2 \pm 5.6$ for the final height of boys and $141.9 \pm 2.8$ for girls $^{9}$. Myrelid et al. reported that individuals aged 0 to 18 years with DS reached average final heights of $161.5 \pm 2.5$ for males and $147.5 \pm 2.8$ for females $^{8}$.

However, because there are no data or methods for assessing the body proportions of subjects with DS, the available international benchmarks were used ${ }^{11}$.

An interesting finding of the present study was the body indices, which allow the relative contribution of the upper body (sitting height) and lower limb (leg length) segments to be assessed. Body index evaluations make it possible to say that children and adolescents with DS have reduced final heights compared with the typical population because of lower growth rates in the lower limbs. In the present study, the children showed reduced leg growth ( $8 \%$ for boys and $6 \%$ for girls, on average) compared with normative values.

The reduced leg growth for both sexes is consistent with the findings of Rarick and Seefeldt, who reported that adolescents with DS have less vigorous growth spurts compared with the typical population because of lower growth rates in the lower limb segments, resulting in a reduced final height ${ }^{10}$.

According to Myrelid, Gustafsson and Ollars et al., reduced height is one of the striking features of individuals with DS, who experience reduced growth rates beginning in the prenatal period. After birth, the growth rate is further reduced between 6 months and 3 years of age, and the growth spurt is reduced and occurs earlier than in the typical population ${ }^{8}$.

Jaswal and Jaswal analyzed the body proportion of the head circumference, height and length of torso and legs of 59 male and female children and adolescents with DS aged 6 to 18 years. The authors compared these characteristics with those of a control group composed of 293 individuals without DS. The results showed that the group with DS had lower values for all anthropometric variables, with standard deviations ranging from -0.04 to 2.36. The major differences were observed in the length of the torso and legs. However, the reduction in the torso length was not proportional to the height. Thus, the authors concluded that the shorter height of people with DS is a result of the reduced leg growth ${ }^{14}$.

Similar findings occurred when the present study's results were compared with those of studies on Turner's Syndrome (TS), which is another genetic syndrome. Hughes, Ribeiro and Hughes assessed the body proportion of 22 TS patients with an average age of $13.8 \pm 2.1$ years. The authors observed a standard deviation of $3.28 \pm 1.0$ for the leg-length segment ${ }^{15}$. Recent studies have found similar results, in which leg length growth was reduced by -2.69 to -3.69 SD on average ${ }^{16}$.

The literature notes the deficit of insulin-like growth factor 1 (IGF-1), which is primarily responsible for the actions of the growth hormone $(\mathrm{GH})$, as one of the factors that influences the reduced growth of individuals with DS. GH is produced primarily by the liver, which stimulates cell proliferation and somatic growth ${ }^{17}$.

In a study by Annerén, Tuvemo and CarlssonSkwirut et al., the authors analyzed the influence of $\mathrm{GH}$ treatment on the height of children with DS. The experimental group included 15 boys and girls with DS who ranged in age from 6 to 9 months at the beginning of the 3 -year treatment period. Later, the participants were compared with the control group, which consisted of 15 similar-aged children of both sexes with DS, who did not receive hormonal treatment. The authors found that the average height of 
the experimental group increased from -1.8 to -0.8 SD during $\mathrm{GH}$ treatment, while the control group showed growth-rate decreases of $-1,7$ to -2.2 SD. This result demonstrated that $\mathrm{GH}$ treatment results in normal growth rates in children with $\mathrm{DS}^{18}$.

Gorla, Duarte and Costa et al. conducted a review of the literature related to the growth of children and adolescents with DS. The authors reported that the growth deficit could also be explained by characteristics that are usually present in this population, including zinc deficiency, congenital heart disease, upper airway obstruction during sleep, celiac

\section{REFERENCES}

1. Roizen NJ, Patterson D. Down's syndrome. Lancet. 2003; 12(361):1281-9.

2. Sugayama SMM, Kim CA. Anormalidades Cromossômicas. [Chromosomal abnormalities] In: Setian, N. Endocrinologia Pediátrica Aspectos físicos e metabólicos do recémnascido ao adolescente. São Paulo: Editora Sarvier, 2002; 638-639.

3. Griffiths AJF, Wessler SR, Lewontin RC, Gelbart W. Introdução a Genética [Introduction to genetics]. Guanabara Koogan. 2006; 534.

4. Licastro F, Mariani RA, Faldella G, Carpene E, Guidicini G, Rangoni A. Immune endocrine status and coelic disease in children with Down's Syndrome: relationships with zinc and cognitive efficiency. Brain Res Bull. 2001; 2 (55): 313-17.

5. Coelho CRZ, Loevy HT. Odontological aspects of Down's syndrome. ARS Curandi Odontol. 1986; 3 (8): 9-16.

6. Mugayar LRF. Pacientes portadores de necessidades especiais: manual de odontologia e saúde oral [Patients with special needs: Manual of dentistry and oral health]. São Paulo: Pancast, 2000; 13.

7. Cronk C, Crocker AC, Pueschel SM, Shea AM, Zackai, E, et al. Growth charts for children with Down syndrome: 1 month to 18 years of age. Pediatrics. 1988; 1 (81): 102-110

8. Myrelid A, Gustafsson J, Ollars B, Annerén G. Growth charts for Down' syndrome from birth to 18 years of age. Arch Dis Child. 2002; 2 (87): 97-103.

9. Kimura J, Tachibana K, Imaizumi K, Kurosawa K, Kuroki Y. Londitudinal growth and height velocity of Japanese children with Down's Syndrome. Acta Paediatr. 2003; 9 (92): 1039-1042.

10. Rarick GL, Seefeldt V. Observations from Longitudinal Data on Growth in Stature and Sitting Height of Children with Down's Syndrome. J Ment Defic Res.1974; 1(18): 63-78. disease, thyroid alterations and inadequate nutrition resulting from feeding difficulties ${ }^{19}$.

Based on the findings, it can be concluded that the body proportions for the upper and lower segments of children and adolescents with DS differ from those of the typical population. This difference is observed in the leg length of this group, which exhibited a lower contribution to height when compared with normative values. For the sitting height proportion, the DS group's values were close to the range reported for the population without DS.

11. Ross WD, Wilson NC. A stratagem for proportional growth assessment. Acta Pediátrica. 1974; 1(28): 169-182.

12. De la Rosa, FJB, Rodriguez-añez CR. O estudo das características físicas do homem por meio da proporcionalidade [The study of the physical characteristics of men by means of proportionality]. Rev Bras Cine Des Hum. 2002; 1(4): 53-66.

13. Guedes DT, Guedes JERP. Manual prático para avaliação em Educação Física [Practical manual for evaluation in physical education]. Editora Manole, 2006; 153-4.

14. Jaswal S, Jaswal IJS. An anthropometric study of body size in Down syndrome. Indian Journal of Pediatrics. $1981 ; 48(1): 81-84$.

15. Hughes PCR, Ribeiro J, Hughes IA. Body proportions in Turner's Syndrome. Archives of Disease in Childhood. 1986; 61: 506-517.

16. Baldin AD, Armani MCA, Morcillo AM, LemosMarini SHV, Baptista MTM, Maciel-Guerra AT, Guerra Júnior G. Proporções corporais em um grupo de pacientes brasileiras com Síndrome de Turner [Body proportions in a group of Brazilian patients with Turner syndrome]. Arq Bras Endocrinol Metab. 2005; 49(4): 529-535.

17. Arnell H, Gustafsson J, Ivarsson SA, Annerén G. Growth and pubertal development in Down syndrome. Acta Paediatr. 1996; 9:1102-6.

18. Annerén G, Tuvemo T, Carlsson-Skwirut C, Lönnerholm T, Bang P, Sara VR, Gustafsson J. Growth hormone treatment in young children with Down's Syndrome: effects on growth and psychomotor development. Arch Dis Child. 1999; 80:334-338.

19. Gorla JI, Duarte E, Costa LT, Fabia F. Crescimento de crianças e adolescentes com Síndrome de Down - uma breve revisão de literature [Growth of children and adolescents with Down syndrome - a brief literature review]. Rev Bras Cineantropom Desempenho Hum. $2011 ; 13(3)$ : 230-237. 